\title{
Electrophoretic assessment of aqueous and serum neurone-specific enolase in retinoblastoma and ocular malignant melanoma
}

\author{
B S F Shine, J Hungerford, B Vaghela, G A K Sheraidah
}

\begin{abstract}
The isoenzyme pattern of enolase was examined in the aqueous humour and serum of patients with retinoblastoma (10 aqueous, 8 sera), malignant melanoma (4 aqueous, 25 sera), and normal subjects undergoing cataract surgery ( 25 aqueous, 30 sera). The assay we used allowed assessment of all three major isoenzymes, including the $\gamma \gamma$ isoenzyme (neurone-specific enolase). No enolase was detectable in normal aqueous; $\alpha \alpha$ isoenzyme was present in the aqueous of one patient with malignant melanoma, while aqueous from all patients with retinoblastoma contained both $\alpha \alpha$ and $\gamma \gamma$. Normal serum contained only an $\alpha \alpha$ band, while serum from patients with retinoblastoma contained $\alpha \alpha, \alpha \gamma$, and $\gamma \gamma$ bands (7 sera, $87 \cdot 5 \%$ ), or $\alpha \alpha$ only ( 1 patient, $12 \cdot 5 \%$ ). All sera from patients with malignant melanoma contained the $\alpha \alpha$ band, with low levels of $\gamma \gamma$ in $16(60 \%)$. In a single patient with Coats's disease $\alpha \alpha$ was present in the serum, but no enolase was detected in aqueous. Increased amounts of $\gamma$-containing isoenzymes of enolase are found in both serum and aqueous from patients with retinoblastoma. In malignant melanoma there is often an increase in serum $\gamma \gamma$ enolase. The assessment of aqueous and serum enolase patterns may be of value in the diagnosis of retinoblastoma and malignant melanoma.
\end{abstract}

The neurone-specific isoenzyme $(\gamma \gamma)$ of enolase is demonstrable in tumours of neuroectodermal origin, such as retinoblastoma and neuroblastoma, ${ }^{12}$ in aqueous humour from patients with retinoblastoma, ${ }^{3}$ and in serum ${ }^{4}$ and urine ${ }^{5}$ from patients with neuroblastoma. Specific information about isoenzymes is yielded by measurement by radioimmunoassay, ${ }^{67}$ enzyme immunoassay, ${ }^{89}$ and electrophoretic separation, ${ }^{10}$ but not by assays based on spectrophotometry ${ }^{111}$ or luminescence. ${ }^{1213}$ Modification ${ }^{14}$ of the electrophoretic assay, with a fluorescent endpoint, makes it more sensitive and rapid, allowing its application to small samples.

We wished to investigate the patterns of enolase isoenzymes in aqueous and serum from patients with malignant ocular tumours, and we describe here our clinical experience with electrophoretic assessment of this enzyme.

Patients, materials and methods

Aqueous humour samples were collected by paracentesis with a tuberculin syringe and disposable 25 gauge needle, with avoidance of blood contamination because of the high enolase activity in erythrocytes. ${ }^{3}$ Samples were collected from enucleated eyes of patients with retinoblastoma and ocular malignant melanoma. A simultaneous serum specimen was drawn, care being taken to avoid haemolysis. Control aqueous samples were taken from patients undergoing cataract extraction at the time of entry into the anterior chamber. All samples were stored at $-40^{\circ} \mathrm{C}$ until assay.

Adenosine diphosphate (ADP), adenosine monophosphate (AMP), nicotinamide adenine dinucleotide phosphate (NADP), 2-phosphoglycerate, hexokinase (EC 2.7.1.1), glucose-6phosphate dehydrogenase (EC 1.1.1.49, from yeast), and pyruvate kinase (EC 2.7.1.40, from rabbit muscle) were obtained from BoehringerMannheim (Mannheim, FRG). Magnesium chloride hexahydrate, potassium chloride, and sucrose were obtained from Sigma Ltd, Poole, England. Cellulose acetate plates (ISO Flur Titan III) and electrophoretic buffer (Electra HR) were obtained from Helena Laboratories, Beaumont, Texas, USA. Electrophoresis tank and power pack (Vokam 2541) were obtained from Shandon Southern Products Ltd, Runcorn, Cheshire, England.

The visualisation reagent contained (per litre) trometamol (Tris) $\mathrm{HCi}$ (pH 7.4, $50 \mathrm{mmol}$ ), $\mathrm{MgCi}_{2}$ (2 mmol), $\mathrm{KCi}(20 \mathrm{mmol})$, glucose (2 $\mathrm{mmol})$, ADP $(90 \mu \mathrm{mol})$, AMP $(20 \mathrm{mmol})$, $\mathrm{NADP}^{+}(0.5 \mathrm{mmol})$, phosphoglycerate $(1 \cdot 2$ mmol), pyruvate kinase (4 KU), hexokinase ( 7 $\mathrm{KU})$, and glucose-6-phosphate dehydrogenase (3.5 KU). To minimise diffusion, sucrose was dissolved in this reagent to give a final concentration of $300 \mathrm{~g} / \mathrm{l}$. Aliquots of $1 \mathrm{ml}$ of the solution were stored at $-20^{\circ} \mathrm{C}$ and thawed immediately before use.

For isoenzyme analysis, two cellulose acetate plates ( 76 by $60 \mathrm{~mm}$ ) were soaked for 30 minutes

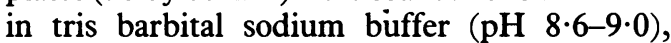
removed, and blotted. To one (the sample plate), $1 \mu \mathrm{l}$ of sample was applied near the cathodic end of the plate, and electrophoresis was carried out in tris barbital sodium buffer at $300 \mathrm{~V}$ for 7 minutes at room temperature. At the same time, the other (substrate) plate was placed membrane side up on a clean glass slide and $1 \mathrm{ml}$ of isoenzyme reagent was poured on to the surface and allowed to soak for the period of electrophoresis. Following electrophoresis the sample plate was carefully placed on the substrate plate with the two wet surfaces apposed. The plates were compressed between prewarmed $\left(37^{\circ} \mathrm{C}\right)$ glass plates and incubated at $37^{\circ} \mathrm{C}$ for 25 minutes. The plates were separated and dried at approxi- 
TABLE I Samples analysed for enolase isoenzymes

\begin{tabular}{lll}
\hline Subjects & Fluid & Number \\
\hline 'Nomal' & Serum & 30 \\
Malignant melanoma & Aqueous & 25 \\
Retinoblastoma & Serum & 25 \\
& Aqueous & 4 \\
Coats's disease & Serum & 8 \\
& Aqueous & 10 \\
& Serum & 1 \\
& Aqueous & 1 \\
\hline
\end{tabular}

mately $57^{\circ} \mathrm{C}$ for 10 minutes. The fluorescence of NADPH thus produced was stable for at least 60 minutes at room temperature and for up to 1 month at $-20^{\circ} \mathrm{C}$. The fluorescent intensity of the bands was assessed visually with a UV lamp with maximum output at $365 \mathrm{~nm}$. Plates were also scanned by means of a Perkin Elmer LS- 5 fluorometer, with scanning attachment and output to a chart recorder $\left(\lambda_{\mathrm{ex}} 360 \mathrm{~nm}, \lambda_{\mathrm{em}} 440 \mathrm{~nm}\right)$.

\section{Results}

A maximum of three bands were detected by this procedure. The slowest band represents the $\alpha \alpha$ isoenzyme, the intermediate band $\alpha \gamma$ isoenzyme, and the anodic band $\gamma \gamma$ isoenzyme. ${ }^{14}$ Bands were visible only if 2-phosphoglycerate was included in the substrate medium, indicating that the enzyme was enolase. Visual assessment of the levels in each band appeared to correlate well with those obtained by scanning.

In total, 64 serum and 39 aqueous samples were examined (Table I). No enolase was detected in normal aqueous humour, and normal serum contained only the $\alpha \alpha$ band with relative intensity ranging from $1+$ to $2+$. Aqueous humour from all eyes with retinoblastoma contained $\alpha \alpha$ and $\gamma \gamma$ bands, with one sample also containing an intermediate $(\alpha \gamma)$ band (Fig 1). There was considerable variation in the relative intensities of the individual bands. Serum from all retinoblastoma patients contained an $\alpha \alpha$ band, $7 / 8(87 \cdot 5 \%)$ also containing $\alpha \gamma$ and $\gamma \gamma$ bands (Fig 2).

An $\alpha \alpha$ band was visible in aqueous humour from one patient of the four with malignant melanoma, but in none could $\alpha \gamma$ or $\gamma \gamma$ be demonstrated. The $\alpha \alpha$ band was present in the

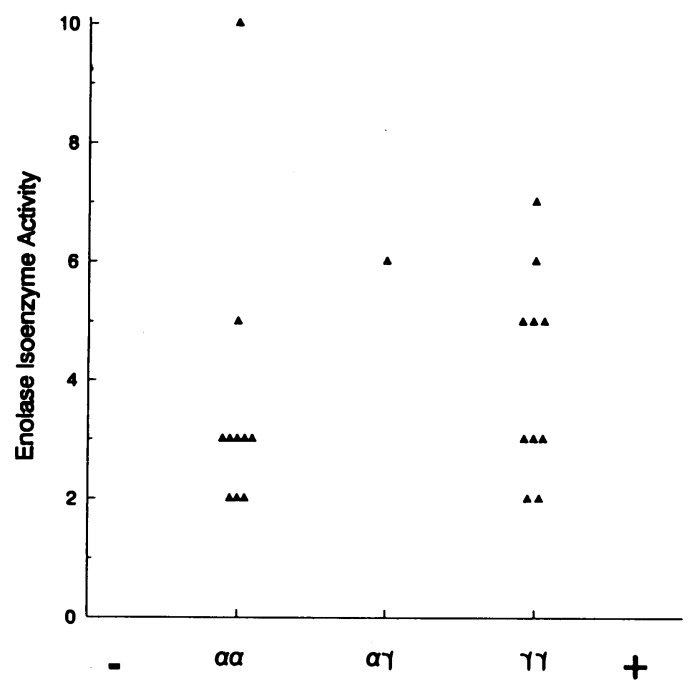

Figure 1: Levels of enolase isoenzymes in aqueous from patients with retinoblastoma.

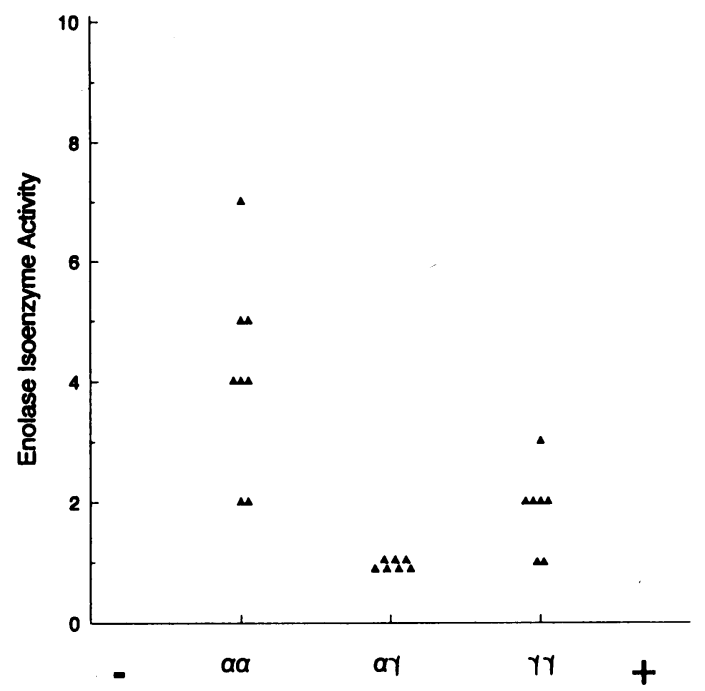

Figure 2: Levels of enolase isoenzymes in serum from patients with retinoblastoma.

serum of all 25 malignant melanoma patients, with relative intensities ranging from $1+$ to $2+$, and in $16 \gamma \gamma(1+)$ was also present (Fig 3). In a single case of Coats's disease, an $\alpha \alpha$ band was present in the serum with no enzyme visible in the aqueous.

\section{Discusssion}

Enolase (2-phospho-D-glycerate hydrolase, EC 4.2.1.11) is widely distributed in tissues, and reversibly catalyses the conversion of 2-phosphoglycerate to phosphoenol pyruvate. Its isoenzymes are dimers consisting of two subunits coded for by three gene loci $\left(\alpha, \beta\right.$, and $\left.\gamma^{11}\right)$. In most adult tissues only the $\alpha \alpha$ dimer is present, while in adult muscle and heart the $\beta \beta$ dimer predominates though $\alpha \beta$ hybrids are demonstrable in the heart. ${ }^{10}$ Since the $\gamma$ subunit was previously believed to be expressed exclusively in mature neurones, $\gamma \gamma$ isoenzyme was designated neurone-specific enolase (NSE). However, low levels of NSE are present in some non-neuronal tissues. ${ }^{15} 16$ The enzyme is not bound to cellular membranes and probably escapes freely following cell injury. $\gamma$-Subunits (that is, $\alpha \gamma$ and $\gamma \gamma^{17}$ ) containing enolase isoenzymes have been

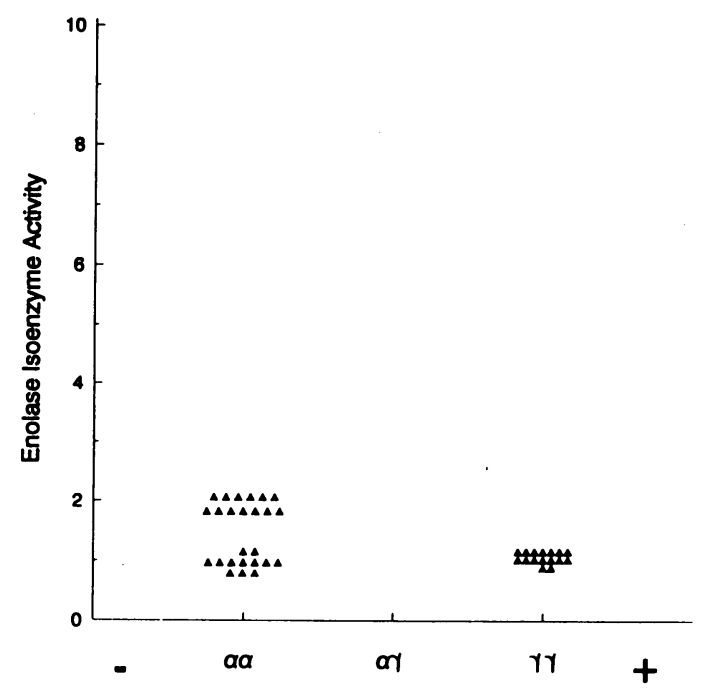

Figure 3: Levels of enolase isoenzymes in serum from patients with ocular malignant melanoma. 
reported to be increased in the serum of patients with neuroblastoma, ${ }^{418} 19$ medullary carcinoma of the thyroid, ${ }^{20}$ and small-cell carcinoma of the lung, ${ }^{21}{ }^{22}$ in urine of patients with neuroblastoma, and in the aqueous of patients with retinoblastoma. ${ }^{319}$

Methods for the measurement of enolase activity in tissues and biological fluids include spectrophotometric $^{1011}$ and bioluminescence ${ }^{1213}$ assays for total enzyme, and radioimmunoassay $^{67}$ enzyme immunoassay, ${ }^{89}$ immunohistochemistry,' and electrophoretic separation followed by colorimetric visualisation, ${ }^{13}$ for measurement of isoenzymes. A modification of the eletrophoresis method ${ }^{14}$ with fluorescence scanning makes it sensitive enough for use on small samples, with assessment of all isoenzymes within one hour.

Retinoblastoma is the commonest malignancy of infancy. It has features of both glial and neuroectodermal origin ${ }^{123}$ and may be unilateral or bilalateral. With appropriate therapy in the early stages the prognosis is good. ${ }^{24}$ Occasional spontaneous regression has been reported. ${ }^{25}$ Correct diagnosis, without recourse to biopsy, is vital, since it is undesirable both to enucleate an eye for a benign condition and to miss a fatal, though potentially curable, malignant tumour. Rates of error worldwide, in the diagnosis of retinoblastoma have been estimated to be $25 \% .{ }^{26}$ If doubt about the diagnosis still exists after tests such as a CT scan have been performed, methods such as the assay of aqueous humour enzymes have been advocated. ${ }^{27-29}$ However, although increased levels of serum and aqueous humour lactate dehydrogenase are often present in retinoblastoma, raised aqueous enzyme levels may be found in other conditions, such as Coats's disease. $^{3031}$ Aqueous levels of $\gamma$-containing enolase isoenzyme have been shown by radioimmunoassay ${ }^{3}$ to be raised in retinoblastoma. Paracentesis of the aqueous humour is sometimes necessary for the diagnosis of both primary $^{32} 33$ and secondary ${ }^{3435}$ anterior segment malignant tumours, though it is associated with a slightly increased risk of tumour dissemination..$^{36}$ In contrast, aspiration of vitreous, subretinal fluid, or tumour cyst material has been strongly discouraged. ${ }^{32} 33$

Using an electrophoretic assay ${ }^{14}$ we have demonstrated different enolase isoenzyme patterns in aqueous humour and serum. Three bands were identified, corresponding to those previously reported to be $\alpha \alpha, \alpha \gamma$ and $\gamma \gamma$ isoenzymes. Aqueous from patients with retinoblastoma contains $\alpha \alpha$ and $\gamma \gamma$ bands, while their serum often contains all three bands. The $\gamma$ bands were absent from normal sera and normal aqueous but were faintly present as the $\gamma \gamma$ band in serum from two-thirds of patients with malignant melanoma. There were no differences between the sexes.

The presence of raised levels of NSE in serum and aqueous from patients with retinoblastoma is expected because of the presumed neuroectodermal origin of this tumour and its previous demonstration in tumour tissue. ${ }^{12}$ Malignant melanoma arises from pigmented cells, in which NSE has been reported not to occur, ${ }^{37}$ though Royds and colleagues ${ }^{38}$ have identified the enzyme in malignant melanoma tissue. The existence of a faint $\gamma \gamma$ band in serum from patients with malignant melanoma may be due to leakage from the tumour, direct damage to the retina from raised intraocular pressure, or to metastatic spread.

Retinoblastoma is associated with increased levels of $\gamma \gamma$-enolase in serum and aqueous. While serum levels may be of diagnostic help, there may be occasions when aqueous parcentesis is necessary for diagnosis. Because of the risk of tumour spread it should be reserved for cases where there is serious doubt about the diagnosis. The presence of a faint $\gamma \gamma$ band in serum from patients with malignant melanoma may also be of diagnostic value. However, further studies (both quantitative and qualitative) need to be performed on a larger population to assess the full potential of the assay.

1 Kivela T. Neuron-specific enolase in retinoblastoma. An immunochemical study. Acta Ophthalmol (KGL) 1987; 64: $19-25$

2 Terenghi G, Polak JM, Ballesta J, et al. Immunocytochemistry of neuronal and glial markers in retinoblastoma. Virchows $\operatorname{Arch}(A) 1984 ; 404: 61-73$

3 Nakajima T, Kato K, Kaneko A, Tsumuraya M, Morinaga S, Shimosato $\mathrm{Y}$. High concentrations of enolase, alpha and gamma subunits, in the aqueous humour in cases of retinoblastoma. Am F Ophthalmol 1986; 101: 102-6.

4 Zeltser PM, Marangos PJ, Evans AE, Schreider SL. Serum neuron-specific enolase in children with neuroblastoma. Relationship to stage and disease course. Cancer 1986; 57: $1230-4$.

5 Goto Y-I, Hashimoto K, Tada K. Urine neuron-specific enolase and its clinical implication in patients with neuroblastoma. Tohoku f Exp Med 1986; 149: 67-72.

6 Parma AM, Marangos PPJ, Goodwin FK. A more sensitive radioimmunoassay for neuron-specific enolase suitable for cerebrospinal fluid determinations. F Neurochem 1981; 36 : 1093-6.

7 Brown KW, Kynoch PAM, Thompson RJ. Immunoreactive nervous system specific enolase (14-3-2 protein) in human serum and

8 Kato K, Suzuki F, Umeda Y. Highly sensitive immunoassays for three forms of rat brain enolase. 7 Neurochem 1981; 36: 793-7.

9 Kato K, Asai R, Schimizu A, Suzuki F, Ariyoshi Y. Immunoassay of three enolase isoenzymes in human serum and in blood cells. Clin Chim Acta 1983: 127: 353-36.

10 Rider CC, Taylor CB. Enolase isoenzymes in rat tissues. Electrophoretic, chromatographic, immunological and kinetic properties. Biochim Biophys Acta 1974; 365: 285300.

11 Wold F. The enzymes. 3rd Ed. New York and London: Academic Press, 1971; 5: 499-535.

12 Viallard JL, Murthy MRV, Dastugue B. Ultramicro bioluminescence assay of enolase. Application to human cerebrospinal fluid. Neurochem Res 1985; 10: 1555-6.

13 Wevers RA, Jacobs AAC, Hommes OR. A bioluminescence assay for enolase (EC4.2.1.11) activity in human serum and cerebrospinal fluid. Clin Chim Acta 1983; 135: 159-68.

14 Viallard JF, Murthy MRV, Dastugue B. Rapid electrophoretic determination of neuron-specific enolase isoenzymes in serum. Clin Chem 1986; 32: 593-6.

15 Hullin DA, Brown KB, Kynoch PAM, Smith C, Thompson RJ. Purification, radioimmunosassy and distribution of human brain 14-3-2 protein (nervous system specific enolase) in human tissues. Biochim Biophys Acta 1980; 628: 98-108.

16 Kato K, Ishigura Y, Suzuki F, Ito A, Semba R. Distribution of nervous system-specific enolase isozymes in human serum and in blood cells. Clin Chim Acta 1982; 127: 353-63.

17 Bock E, Dissing J. Demonstration of enolase activity connected to the brain specific protein 14-3-2. Scand 7 Immunol $1975 ; 4: 31-6$.

18 Ishiguro $Y$, Kato K, Shimizu A, Ito T, Magya M. High levels of immunoreactive nervous system-specific enolase in sera of patients with neuroblastoma. Clin Chim Acta 1982; 121 173-88.

19 Beemer FA, Vlug AM, van Veelen CW, Rijksen G, Staal GEJ. Isoenzyme pattern of enolase of childhood tumors. Cancer 1984; 54: 293-6.

20 Oskam R, Rijksen G, Cees J, Lips M, Staal G E J. Enolase isoenzymes in differentiated and undifferentiated medullary thyroid carcinomas. Cancer 1985; 55: 934-9.

21 Akoun GM, Scarna HM, Milleron BJ, Penichou MP, Herman DP. Serum neuron-specific enolase. A marker for disease extent and response to therapy for small cell lung cancer. Chest 1985; 87: 39-43.

22 Viallard JL, Caillard D, Kantelip B, Molina C, Dastugue B. Enzymatic determination of serum neuron-specific enolase in small cell lung cancers. Chest 1988; 93: 1225-33. 
23 Rodrigues MM, Wiggert B, Shields J, et al. Retinoblastoma. Immunohistochemistry and cell differentiation. Ophthalmology 1987; 94: 378-87.

24 Albert DM. Historic review of retinoblastoma. Ophthalmology 1987; 94: 654-62.

25 Abramson DH. Retinoma, retinocytoma, and the retinoblastoma gene. Arch Ophthalmol 1983; 101: 1517-8.

26 Margo CE, Zimmerman LE. Retinoblastoma: the accuracy of clinical diagnosis in children treated by enucleation. $f$ Pediatr Ophthalmol Strabismus 1983; 20: 227-9.

27 Swartz M, Herbst RW, Goldberg MF. Aqueous humor lactic acid dehydrogenase in retinoblastoma. Am $\mathcal{F}$ Ophthalmol 1974; 78: 612-7.

28 Das A, Roy IS, Maitra TK. Lactate dehydrogenase level and protein pattern in the aqueous humour of patients with retinoblastoma. Can 7 Ophthalmol 1983; 18: 3379.

29 Dayal Y, Goyal JL, Jaffery NF, Agarwal HC. Lactate dehydrogenase levels in aqueous humor and serum in retinoblastoma. Fpn $\mathcal{F}$ Ophthalmol 1985; 29: 417-22.

30 Jakobiec FA, Abramson D, Scher R. Increased aqueous lactate dehydrogenase in Coats' disease. Am $\mathcal{F}$ Ophthalmol lactate dehydrogen
31 Lifshitz T, Tessler Z, Maor E, Yassur Y. Increased aqueous actic dehydrogenase in Coats' disease. Ann Ophthalmol 1987; 19: 116-9.

32 Duke-Elder S. System of ophthalmology. London: Kimpton, 1966; 9: 900-2.

33 Duke Elder S. System of ophthalmology. London: Kimpton, 1966; 10: 710-2.

34 Scholz R, Green WR, Baranano EC, Erozan YS, Montgomery BJ. Metastatic carcinoma to the iris. Diagnosis by aqueous paracentesis and response to irradiation and chemotherapy. Ophthalmology 1983; 90: 1524-7.

5 Woog JJ, Chess J, Albert DM, Dueker DK, Berson FG, Craft J. Metastatic carcinoma of the iris simulating iridocyclitis. Br F Ophthalmol 1984; 68: 167-73.

36 Middleton WH. Diagnosis of metastatic tumors of the anterior ocular segment. Am f Ophthalmol 1952; 35: 132934

37 Molnar ML, Stefansson K, Marton LS, Tripathi RS, Molnar GK. Immunohistochemistry of retinoblastoma in humans. Am f Ophthalmol 1984; 97: 301-7.

38 Royds JA, Rennie IG, Parsons MA, Timperley WR, Taylor $\mathrm{CB}$. Enolase isoenzymes in uveal melanomas - a possible CB. Enolase isoenzymes in uveal melanomas - a possible
parameter of malignancy. Br $\mathcal{F}$ Ophthalmol 1983; 67: 244-8. 